Article

\title{
Study of the Tensile Properties of CFRP Strengthened Steel Plates
}

\author{
Yiyan Lu *, Weijie Li, Shan Li, Xiaojin Li and Tao Zhu \\ Received: 12 November 2015; Accepted: 4 December 2015; Published: 9 December 2015 \\ Academic Editors: Alper Ilki and Masoud Motavalli \\ School of Civil Engineering, Wuhan University, Wuhan 430072, China; leewj@whu.edu.cn (W.L.); \\ lsdlut@163.com (S.L.); lixiaojin1986@sina.cn (X.L.); dino2088@hotmail.com (T.Z.) \\ * Correspondence: yylu901@163.com; Tel./Fax: +86-27-6877-5832
}

\begin{abstract}
This paper presents the experimental results of steel plates strengthened with carbon fiber reinforced polymer (CFRP) sheets under tensile load. The number of CFRP layers (ranging from one to four), strengthening schemes (single-sided and double-sided bonding), and temperatures (ranging from 25 to $120^{\circ} \mathrm{C}$ ) were investigated. Results showed that the number of CFRP layers and strengthening schemes had insignificant effects on failure modes of specimens. The failure modes were dominated by the degradation of resin matrix at temperatures lower than $T_{\mathrm{g}}+10$ or $20^{\circ} \mathrm{C}$, where $T_{\mathrm{g}}$ is the glass transition temperature, and were dominated by the volume decrease of resin matrix at temperatures above that. Through bonding CFRP sheets, the ultimate load and post-elastic stiffness of specimens were significantly increased. However, the increase in the number of CFRP layers also led to the decrease in strengthening and stiffening efficiency. The double-sided strengthened specimens showed more preferable mechanical properties than the single-sided strengthened specimens. As temperature increased, significant decreases in ultimate load and post-elastic stiffness were observed. Analytical modeling to predict the mechanical properties at ambient and elevated temperatures were conducted, respectively. The modeling results were verified by the test data.
\end{abstract}

Keywords: carbon fiber reinforced polymer (CFRP); steel plates; tensile; failure modes; strengthening; stiffening

\section{Introduction}

Fiber reinforced polymer (FRP) composites have gained an increasing use in civil infrastructure applications [1-4]. The preferable mechanical properties of FRP composites include high specific strength, corrosion resistance, ease of transportation and installation, etc. Carbon fiber reinforced polymer (CFRP) composites are the most widely used FRP composites with respect to strengthening steel structures. Compared with the traditional technique by bonding steel plates, the application of CFRP composites avoids the procedure of welding and the occurrence of residual stresses, and is thus beneficial for the fatigue resistance of steel structures.

An increasing number of studies have been conducted on the utilization of CFRP composites in strengthening steel structures [3-6]. Sen et al. [5] conducted research on six steel beams strengthened with 2 or $5 \mathrm{~mm}$ thick CFRP plates. Results demonstrated that bonding CFRP plates significantly increased the ultimate bearing capacity, while its effects on elastic response were relatively modest. Al-Saidy et al. [6] reported obvious increases in post-elastic stiffness of strengthened beams through the use of high modulus CFRP, also confirmed by Fam et al. [7] and Schnerch and Rizkalla [8].

Instead of strengthening the whole structures, some researchers focused on strengthening only steel members, among which steel plates are an example. Steel plates are representative of the tension flanges of steel beams or other tensional elements in the tests. Miller et al. [9] studied 
the stress distribution in CFRP through tensile tests on CFRP-bonded steel plate. Colombi and Poggi [10] conducted research on three double-sided strengthened specimens and three double lap joints, with the aim of reproducing the strengthening of uncracked and cracked tension members. Al-Zubaidy et al. [11] compared the bond characteristics of double strap joints under static and dynamic tensile loads, and investigated the effects of the number of CFRP layers, bond lengths, and loading rates. Bocciarelli et al. [12] and Liu et al. [13] studied the fatigue behavior of CFRP-strengthened steel plates and verified the superiority of CFRP in improving the fatigue resistance of specimens. Li et al. [14] studied the tensile behavior of steel plates bonded with basalt fiber reinforced polymer (BFRP) from the perspective of novel materials.

Despite these research efforts, many aspects of the strengthening effects remain unclear, for example, the number of CFRP layers, the bonding schemes (single-sided bonding and double-sided bonding), and elevated temperatures.

Admittedly, the increase in the number of CFRP layers could significantly increase the strength and stiffness of specimens. However, conclusions vary on the strengthening efficiency of different numbers of CFRP layers, which is expressed as the average failure stress in CFRP layers. Reports on efficiency of stiffening effects are limited. Li et al. [14] reported an almost linear increase in the ultimate bearing capacity of BFRP bonded steel plates as the number of BFRP layers increased from zero to eight. Though the material was BFRP sheets, the results were similar to the strengthening effects of CFRP sheets. In contrast, Tavakkolizadeh and Saadatmanesh [15] reported a decrease in the strengthening efficiency of CFRP strengthened beams, with the average failure stress of CFRP dropping from $75 \%$ of the ultimate tensile strength to $42 \%$ as the number of CFRP layers increased from one to five.

Aside from the number of CFRP layers, the strengthening schemes, including single-sided bonding and double-sided bonding, are also yet to be resolved. This issue is interesting since CFRP could be bonded on both sides of the tension flange of the beam [9]. To the best knowledge of the authors, no comparison has been made of the strengthening and stiffening effects of these two schemes, though each scheme has been studied respectively $[5,10,13]$. Available reports indicated that a double-sided bonding scheme may have better strengthening and stiffening effects. Lu et al. [16] reported a discrepancy in the strain of CFRP and steel after steel yielding through tensile test on CFRP bonded steel plates. The discrepancy, which contributed to the shear strain of bonding adhesive and might even result in premature local adhesive failure, was directly related to the number of CFRP layers bonded on one side of the steel plate [17]. By attaching the CFRP layer on both sides instead of on only one side, the strain discrepancy between CFRP and steel would be decreased, which might be beneficial for the service of strengthened specimens.

The effects of elevated temperatures are also of high concern. As temperature rises, resins and adhesives begin to soften, which leads to a sharp reduction in stiffness and strength of CFRP strengthened steel structures. The critical temperature is called the glass transition temperature $\left(T_{\mathrm{g}}\right)$, which ranges between 55 to $120{ }^{\circ} \mathrm{C}$ [18]. Limited research is available for understanding the degradation of CFRP strengthened steel structures at elevated temperatures. Cao et al. [19] studied the tensile properties of CFRP and hybrid FRP at elevated temperatures. They pointed out that the degradation in strength of FRP materials at elevated temperatures was due to the softening of the resin matrix, which lost the ability to transfer load among fibers that were in an originally wavy state. Mouritzand Gibson [20] proposed the following formula for modeling the degradation of FRP:

$$
P(T)=\left(\frac{P_{\mathrm{U}}+P_{\mathrm{R}}}{2}-\frac{P_{\mathrm{U}}-P_{\mathrm{R}}}{2} \tanh \left(k\left(T-T^{\prime}\right)\right)\right) R^{n}
$$

where $P(T)$ is a particular property at temperature $T ; P_{\mathrm{U}}$ and $P_{\mathrm{R}}$ are the unrelaxed (low temperature) and relaxed (high temperature) values of that property, respectively; $k$ is a constant describing the length of relaxation; $T^{\prime}$ is the temperature when a $50 \%$ reduction in the property's value is observed; and $R^{n}$ is a power law factor accounting for resin decomposition and equals one when 
the property related to is tensile strength. This model was validated by Chowdhury et al. [21]. Cree et al. [18] reported a fibrous fracture failure mode when the temperature rose above $200{ }^{\circ} \mathrm{C}$ through tests on CFRP composites. The fibrous fracture, which showed a random distribution of fibers rather than small pieces, was believed to be indicative of the increased softening of epoxy resin. Nguyen et al. [22] conducted tests on CFRP/steel double strap joints. As temperature rose, the failure mode of steel/CFRP double strap joints changed from CFRP delamination (adherend failure) to cohesive debonding failure (adhesive failure). It was therefore concluded that the failure mode at elevated temperatures was dominated by the temperature dependence of the bonding adhesive, and that the change in failure mode was due to the faster degradation rate of the bonding adhesive than that of the resin matrix, though the bonding adhesive and resin matrix were made of the same epoxy. $\mathrm{Li}$ and Wang [23] compared the provisions on properties of steel at elevated temperatures of different guidelines, including ECCS, EC3, AS4100, CECS200, and Japanese standard. Most of the guidelines assumed a constant yield strength of steel when the temperature was below $215^{\circ} \mathrm{C}$.

With an aim to evaluate the effects of these three factors on the failure modes and tensile behavior of strengthened specimens, this paper presents a study on CFRP strengthened steel plates under tensile load. The number of CFRP layers (ranging from one to four), strengthening schemes (single-sided or double-sided bonding), and experimental temperatures (ranging from 25 to $120^{\circ} \mathrm{C}$ ) were investigated. Analytical modeling was also conducted to predict the mechanical behavior at ambient and elevated temperatures, respectively.

\section{Experimental Section}

\subsection{General}

Table 1 lists the details of specimens for ambient and elevated temperature tests. As shown, specimens are categorized into series L, S, and T, which are for study of number of CFRP layers, strengthening schemes, and experimental temperatures, respectively. Specimens of series $\mathrm{L}$ and $\mathrm{S}$ were tested at ambient temperature, while specimens of series $\mathrm{T}$ were tested at temperatures ranging from 25 to $120^{\circ} \mathrm{C}$. Each specimen has three identical replicates in the present paper.

Table 1. Summary of test specimens.

\begin{tabular}{|c|c|c|c|c|}
\hline Series & Specimen & Temperature $\left({ }^{\circ} \mathrm{C}\right)$ & Sequence & Number of CFRP layers \\
\hline \multirow{4}{*}{$\mathrm{L}$} & $\mathrm{C} / \mathrm{S}$ & 25 & $\mathrm{C}+\mathrm{S}$ & 1 \\
\hline & $2 \mathrm{C} / \mathrm{S}$ & 25 & $\mathrm{C}+\mathrm{C}+\mathrm{S}$ & 2 \\
\hline & $3 C / S$ & 25 & $\mathrm{C}+\mathrm{C}+\mathrm{C}+\mathrm{S}$ & 3 \\
\hline & $4 \mathrm{C} / \mathrm{S}$ & 25 & $\mathrm{C}+\mathrm{C}+\mathrm{C}+\mathrm{C}+\mathrm{S}$ & 4 \\
\hline \multirow{3}{*}{$S$} & $4 \mathrm{C} / \mathrm{S}$ & 25 & $\mathrm{C}+\mathrm{C}+\mathrm{C}+\mathrm{C}+\mathrm{S}$ & 4 \\
\hline & $3 \mathrm{C} / \mathrm{S} / \mathrm{C}$ & 25 & $\mathrm{C}+\mathrm{S}+\mathrm{C}+\mathrm{C}+\mathrm{C}$ & 4 \\
\hline & $2 \mathrm{C} / \mathrm{S} / 2 \mathrm{C}$ & 25 & $\mathrm{C}+\mathrm{C}+\mathrm{S}+\mathrm{C}+\mathrm{C}$ & 4 \\
\hline \multirow{12}{*}{$\mathrm{T}$} & $\mathrm{C} / \mathrm{S}$ & 25 & $\mathrm{C}+\mathrm{S}$ & 1 \\
\hline & C/S-T30 & 30 & $\mathrm{C}+\mathrm{S}$ & 1 \\
\hline & C/S-T35 & 35 & $\mathrm{C}+\mathrm{S}$ & 1 \\
\hline & C/S-T40 & 40 & $\mathrm{C}+\mathrm{S}$ & 1 \\
\hline & C/S-T45 & 45 & $\mathrm{C}+\mathrm{S}$ & 1 \\
\hline & C/S-T50 & 50 & $\mathrm{C}+\mathrm{S}$ & 1 \\
\hline & C/S-T55 & 55 & $\mathrm{C}+\mathrm{S}$ & 1 \\
\hline & $\mathrm{C} / \mathrm{S}-\mathrm{T} 60$ & 60 & $\mathrm{C}+\mathrm{S}$ & 1 \\
\hline & C/S-T70 & 70 & $\mathrm{C}+\mathrm{S}$ & 1 \\
\hline & C/S-T80 & 80 & $\mathrm{C}+\mathrm{S}$ & 1 \\
\hline & C/S-T100 & 100 & $\mathrm{C}+\mathrm{S}$ & 1 \\
\hline & C/S-T120 & 120 & $\mathrm{C}+\mathrm{S}$ & 1 \\
\hline
\end{tabular}

1. $\mathrm{C}$ and $\mathrm{S}$ denote CFRP and steel plate, respectively; 2 . Specimens $\mathrm{C} / \mathrm{S}$ and $4 \mathrm{C} / \mathrm{S}$ appear twice in specimen code, with the main purpose for better series illustration, though there are only one group of specimens $\mathrm{C} / \mathrm{S}$ and $4 \mathrm{C} / \mathrm{S}$, respectively; $\mathrm{L}, \mathrm{S}$, and $\mathrm{T}$ refer to sample series for the study of the number of CFRP layers, strengthening schemes, and experimental temperatures, respectively. 


\subsection{Materials}

Materials used for manufacturing specimens included steel plates, unidirectional carbon fiber sheets, and epoxy resin. Mechanical properties of steel plates and CFRP sheets were obtained through tensile coupon tests according to ISO 6892-1 [24] and ASTM D3039 [25], respectively. The CFRP sheets were UT70-20, supplied by Toray of Japan. The properties of epoxy resin were obtained from the supplier. The epoxy resin was WSX, supplied by Wudajucheng, a company of China, with the $T_{\mathrm{g}}$ being $50{ }^{\circ} \mathrm{C}$ according to the manufacturer's data sheet. Mechanical properties of these materials are listed in Table 2.

Table 2. Material properties.

\begin{tabular}{cccccc}
\hline Material & $\begin{array}{c}\text { Thickness } \\
(\mathbf{m m})\end{array}$ & $\begin{array}{c}\text { Young's modulus } \\
\mathbf{( G P a )}\end{array}$ & $\begin{array}{c}\text { Yield strength } \\
\mathbf{( M P a )}\end{array}$ & $\begin{array}{c}\text { Ultimate } \\
\text { strength } \mathbf{( M P a})\end{array}$ & $\begin{array}{c}\text { Failure strain } \\
\mathbf{( \% )}\end{array}$ \\
\hline Steel plate & 2 & 185 & 271 & 364 & 28 \\
CFRP sheet & 0.111 & 252 & - & 3,553 & 1.4 \\
Epoxy resin & - & $\geqslant 2.5$ & - & $\geqslant 30.0$ & - \\
\hline
\end{tabular}

\subsection{Specimens}

Figure $1 \mathrm{a}, \mathrm{b}$ show the geometry of specimens for tests at ambient temperature and at elevated temperatures. The gauge length of specimens was $120 \mathrm{~mm}$. Extra steel teeth are designed to place the clip-on extensometer for double-sided strengthened specimens. A copper rod, which has a low coefficient of thermal expansion $\left(1.65 \times 10^{-5} /{ }^{\circ} \mathrm{C}\right)$, together with a displacement gauge, was adopted for measuring the strain of specimens at elevated temperatures. The change from clip-on extensometer to copper rod and displacement gauge was due to the fact that the extensometer could not be placed in the temperature chamber, which was for heating the specimens, and that the measuring results of extensometer were easily affected by temperature when the temperature was high (more than $60^{\circ} \mathrm{C}$ ). One end of the steel plates for the temperature test was extended from 60 to $110 \mathrm{~mm}$ to place the displacement gauge.

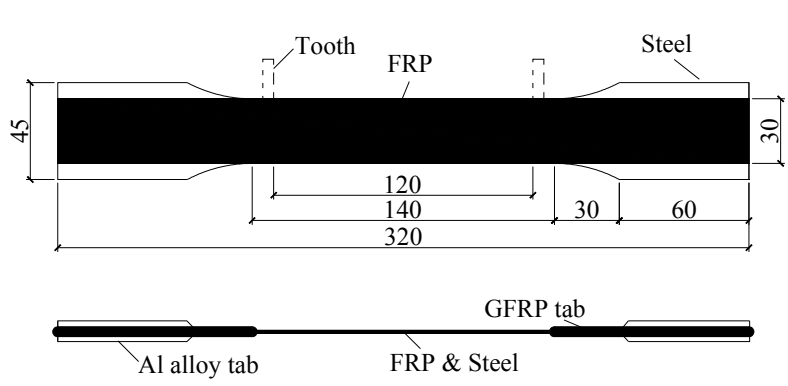

(a)

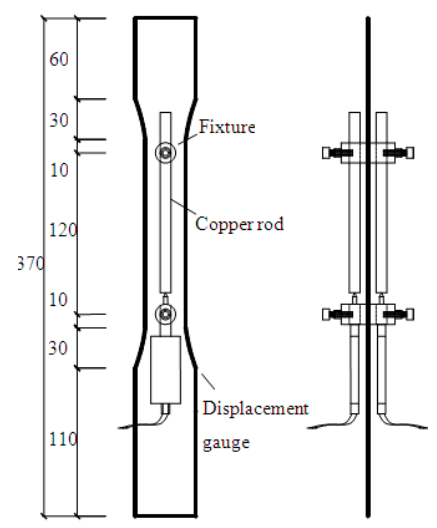

(b)

Figure 1. Geometry of specimens: (a) specimens for ambient temperature; and (b) specimens for elevated temperatures (unit: $\mathrm{mm}$ ).

Specimens were fabricated at room temperature through hand lay-up technique. The steel plates were uniformly roughened with fine emery paper and cleaned with ethanol prior to the application of epoxy resin to ensure a sound bonding and prevent contaminants. The two-part epoxy resin was mixed with the weight ratio being 4:1 (resin/hardener) according to manufacturer's requirements. Carbon fiber sheets were impregnated in the epoxy resin and then placed upon the surface of steel plates. Pressure was applied on CFRP sheets to ooze out voids and excess resin. GFRP tabs were then 
bonded to the tab portion at the surface of CFRP, followed by the bonding of aluminum alloy tabs. GFRP tabs were used to contribute to better load transferring capability at the tab portion. Pressure was applied on aluminum alloy tabs after the bonding process. For double-sided strengthened specimens, the steel plate with one side bonded was cured at room temperature for one day before the bonding of the other side. When both sides were completed, binder clips were attached to the specimens throughout the length. Specimens were cured at room temperature for seven days before testing.

\subsection{Test Setup and Instrumentation}

The schematic view of test setup is shown in Figure 2. Tensile tests were carried out through a universal testing machine, with the crosshead speed being $1 \mathrm{~mm} / \mathrm{min}$. A spherical hinge was used to connect the load cell and the clamp of the universal testing machine for better alignment.

Strain gauges and the clip-on extensometer, which had a measure range of $25 \mathrm{~mm}$ and a linearity error of $\pm 0.10 \%$, were used to measure the longitudinal strain for tests at ambient temperature. The strain for tests at elevated temperatures was measured by a displacement gauge, with the measurement range being $30 \mathrm{~mm}$ and the linearity error being $\pm 0.10 \%$. The temperature was controlled by the chamber, which has a probe for sensing the air temperature inside. Specimens for elevated temperature tests were preheated for $20 \mathrm{~min}$ in the chamber and kept in the chamber throughout the tensile process.

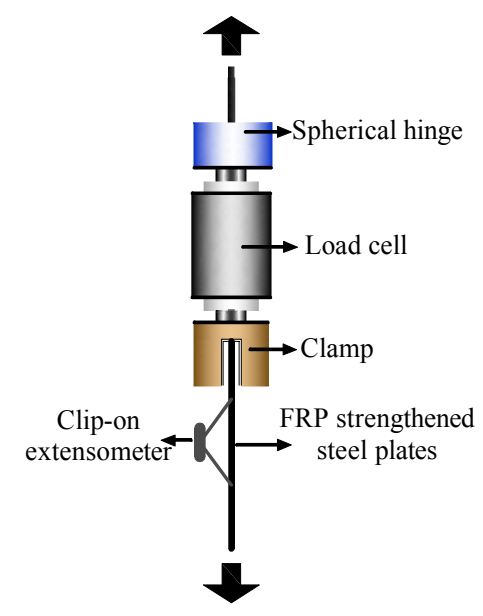

(a)

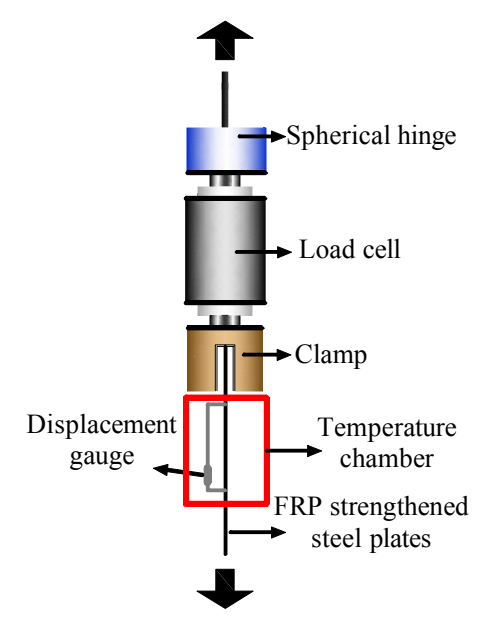

(b)

Figure 2. Schematic view of test setup: (a) test setup for ambient temperature; and (b) test setup for elevated temperatures.

\section{Results and Discussion}

Tensile results are summarized in Table 3. Except for the data of specimens $3 \mathrm{C} / \mathrm{S}$ and $3 \mathrm{C} / \mathrm{S} / \mathrm{C}$, each value is the average of three replicates' experimental results. The values of specimens $3 \mathrm{C} / \mathrm{S}$ and $3 \mathrm{C} / \mathrm{S} / \mathrm{C}$ in Table 3 are the average of two replicates, as one replicate failed prematurely and the data became unavailable. The premature failure might be due to in-plane bending, which was caused by irregular adhesive thickness at tab ends and misalignment between grips and specimens. The premature failure highlights the importance of specimen preparation and placing. The mechanical values of steel plates were theoretical results based on coupon test data. They are listed for better illustration of strengthening and stiffening effects. In this paper, the yield load of specimens is defined as the load when steel yields, and the ultimate load as the load when the first significant drop in the load-displacement curves is observed. One exception to this is that the yield load of steel plate is defined as its ultimate load, as strengthened specimens usually failed when steel was still in the yield plateau or not far from that. 
Table 3. Test results of specimens at ambient temperature.

\begin{tabular}{|c|c|c|c|c|c|c|c|c|c|c|c|c|c|c|}
\hline \multirow{2}{*}{ Series } & \multirow{2}{*}{ Specimen } & \multicolumn{3}{|c|}{$K_{I}$} & \multicolumn{3}{|c|}{$P_{\mathrm{y}}$} & \multicolumn{3}{|c|}{$K_{\text {II }}$} & \multicolumn{3}{|c|}{$P_{\mathrm{u}}$} & \multirow{2}{*}{$\begin{array}{c}\text { Failure } \\
\text { mode }\end{array}$} \\
\hline & & $\begin{array}{c}\text { Exp. } \\
(\mathrm{kN} / \mathrm{mm})\end{array}$ & CV (\%) & $\begin{array}{l}\text { Theo. } \\
\text { (kN/mm) }\end{array}$ & $\begin{array}{l}\text { Exp. } \\
(\mathrm{kN})\end{array}$ & CV (\%) & $\begin{array}{l}\text { Theo. } \\
(\mathrm{kN})\end{array}$ & $\begin{array}{c}\text { Exp. } \\
(\mathrm{kN} / \mathrm{mm})\end{array}$ & CV (\%) & $\begin{array}{l}\text { Theo. } \\
\text { (kN/mm) }\end{array}$ & $\begin{array}{l}\text { Exp. } \\
(\mathrm{kN})\end{array}$ & CV (\%) & $\begin{array}{l}\text { Theo. } \\
\text { (kN) }\end{array}$ & \\
\hline \multirow{5}{*}{$\mathrm{L}$} & $S$ & - & - & 92.5 & - & - & 16.3 & - & - & 0 & - & - & 16.3 & - \\
\hline & $\mathrm{C} / \mathrm{S}$ & 95.9 & 9.1 & 99.5 & 17.3 & 5.3 & 17.5 & 7.0 & 11.4 & 7.0 & 28.6 & 6.7 & 28.1 & $\mathrm{LF}+\mathrm{D}$ \\
\hline & $2 \mathrm{C} / \mathrm{S}$ & 106.0 & 7.8 & 106.5 & 18.6 & 11.2 & 18.7 & 12.1 & 12.3 & 14.0 & 39.7 & 11.1 & 39.9 & $\mathrm{LF}+\mathrm{D}$ \\
\hline & $3 \mathrm{C} / \mathrm{S}$ & 103.9 & 9.4 & 113.5 & 19.4 & 8.7 & 19.9 & 17.2 & 8.8 & 21.0 & 48.1 & 10.3 & 51.8 & $\mathrm{LF}+\mathrm{D}$ \\
\hline & $4 \mathrm{C} / \mathrm{S}$ & 94.9 & 7.2 & 120.5 & 20.2 & 4.9 & 21.2 & 20.7 & 12.1 & 28.0 & 56.0 & 12.9 & 63.6 & $\mathrm{LF}+\mathrm{D}$ \\
\hline \multirow{3}{*}{$S$} & $4 \mathrm{C} / \mathrm{S}$ & 94.9 & 7.2 & 120.5 & 20.2 & 4.9 & 21.2 & 24.3 & 12.1 & 28.0 & 56.0 & 12.9 & 63.6 & $\mathrm{LF}+\mathrm{D}$ \\
\hline & $3 \mathrm{C} / \mathrm{S} / \mathrm{C}$ & 118.7 & 9.8 & 120.5 & 20.4 & 5.7 & 21.2 & 28.9 & 10.4 & 28.0 & 59.7 & 9.1 & 63.6 & $\mathrm{LF}+\mathrm{D}$ \\
\hline & $2 \mathrm{C} / \mathrm{S} / 2 \mathrm{C}$ & 120.3 & 5.6 & 120.5 & 20.6 & 8.8 & 21.2 & 33.0 & 15.7 & 28.0 & 63.2 & 4.5 & 63.6 & $\mathrm{LF}+\mathrm{S}+\mathrm{D}$ \\
\hline \multirow{12}{*}{$\mathrm{T}$} & $\mathrm{C} / \mathrm{S}$ & 95.9 & 9.1 & - & 17.3 & 5.3 & - & 7.0 & 11.4 & 7.0 & 28.6 & 6.7 & 27.6 & $\mathrm{LF}+\mathrm{D}$ \\
\hline & C/S-T30 & 93.4 & 8.8 & - & 17.3 & 6.1 & - & 6.8 & 12.8 & 6.9 & 27.4 & 10.2 & 27.0 & $\mathrm{LF}+\mathrm{S}+\mathrm{D}$ \\
\hline & C/S-T35 & 93.3 & 7.3 & - & 17.2 & 10.0 & - & 7.1 & 11.9 & 6.7 & 25.5 & 9.0 & 26.1 & $\mathrm{LF}+\mathrm{S}+\mathrm{D}$ \\
\hline & C/S-T40 & 92.7 & 9.9 & - & 17.0 & 4.3 & - & 5.6 & 15.6 & 6.1 & 24.1 & 13.3 & 24.7 & $\mathrm{LF}+\mathrm{S}+\mathrm{D}$ \\
\hline & C/S-T45 & 93.1 & 5.6 & - & 16.9 & 11.9 & - & 5.4 & 13.2 & 5.1 & 23.9 & 7.6 & 23.3 & IF \\
\hline & C/S-T50 & 92.8 & 8.3 & - & 16.8 & 6.7 & - & 4.1 & 9.9 & 4.1 & 22.1 & 8.9 & 22.1 & $\mathrm{IF}+\mathrm{S}$ \\
\hline & C/S-T55 & 90.4 & 7.5 & - & 16.2 & 5.9 & - & 3.3 & 10.4 & 3.5 & 21.5 & 2.0 & 21.3 & IF \\
\hline & C/S-T60 & 91.0 & 5.8 & - & 16.1 & 8.2 & - & 3.1 & 5.8 & 3.3 & 20.5 & 3.8 & 20.9 & IF \\
\hline & $\mathrm{C} / \mathrm{S}-\mathrm{T} 70$ & 89.5 & 5.9 & - & 16.3 & 11.3 & - & 3.2 & 3.4 & 3.2 & 21.2 & 4.1 & 20.5 & IF \\
\hline & C/S-T80 & 90.5 & 4.7 & - & 16.0 & 5.8 & - & 3.4 & 4.1 & 3.2 & 20.7 & 3.9 & 20.5 & IF \\
\hline & C/S-T100 & 89.3 & 3.5 & - & 16.0 & 7.6 & - & 3.0 & 1.7 & 3.2 & 19.7 & 2.1 & 20.5 & IF \\
\hline & C/S-T120 & 90.2 & 3.8 & - & 16.1 & 1.9 & - & 3.3 & 3.0 & 3.2 & 20.4 & 5.6 & 20.5 & FF \\
\hline
\end{tabular}

1. $K_{\mathrm{I}}=$ Elastic stiffness; $P_{\mathrm{y}}=$ yield load; $K_{\mathrm{II}}=$ post-elastic stiffness; $P_{\mathrm{u}}=$ ultimate load; Exp. = experimental value; $\mathrm{CV}=$ Coefficient of Variation; and Theo. $=$ theoretical value,

respectively; 2 . Failure mode: $\mathrm{LF}=$ lateral fracture; $\mathrm{D}=$ steel-adhesive debonding; $\mathrm{S}=$ longitudinal splitting; $\mathrm{IF}=$ irregular fracture; and $\mathrm{FF}=$ fibrous fracture 


\subsection{Failure Modes}

The failure modes of all specimens are listed in Table 3, with typical failed specimens shown in Figure 3.

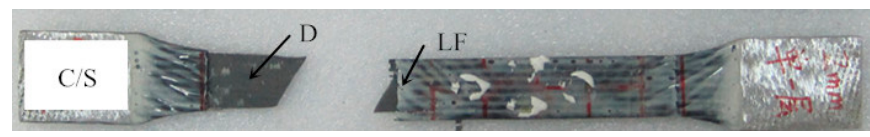

(a)

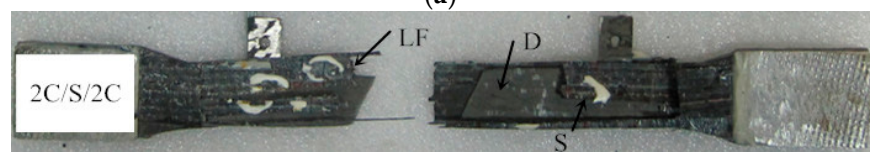

(b)

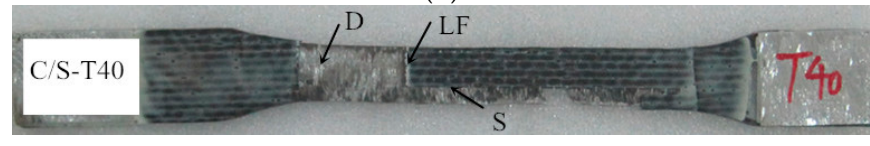

(c)

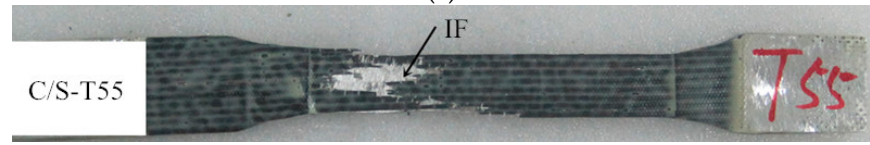

(d)

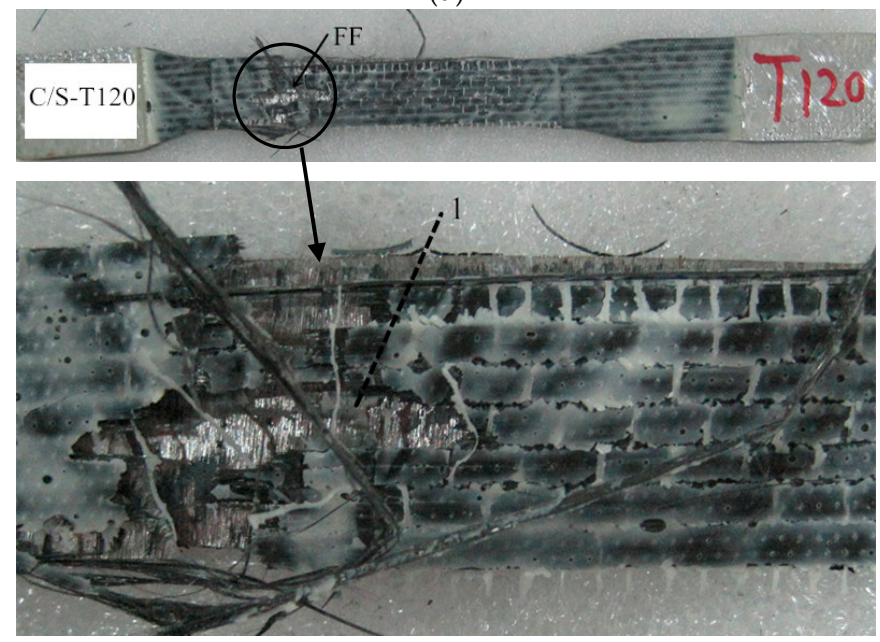

(e)

Figure 3. Failure modes of selected specimens: (a) C/S; (b) 2C/S/2C; (c) C/S-T40; (d) C/S-T55; and (e) C/S-T120.

As noted, the increase in the number of CFRP layers and the change in strengthening schemes did not have observable effects on failure modes. Except for specimen $2 \mathrm{C} / \mathrm{S} / 2 \mathrm{C}$, all specimens of series $\mathrm{L}$ and $\mathrm{S}$ failed in a combined failure mode involving both CFRP lateral fracture and steel-adhesive debonding, with the lateral fracture being predominant. Specimen $2 \mathrm{C} / \mathrm{S} / 2 \mathrm{C}$ showed splitting failure in addition to the two types of failure mentioned above. Misalignment in the application process was believed to be the main contributor to that. The debonding failure observed in specimens did not indicate a premature failure, as CFRP rupture in the middle part of specimens was also observed. The debonding was believed to be due to strain incompatibility between steel and CFRP after the yielding of steel [16], which led to the increase in shear strain of adhesive and caused adhesive shear failure as load increased. The debonding, which occurred at the interface between steel and adhesive instead of between CFRP and adhesive, was indicative of a higher bonding strength between CFRP and adhesive than between steel and adhesive at ambient temperature. 
In comparison, experimental temperatures significantly affected the failure modes. From 30 to $40{ }^{\circ} \mathrm{C}$, the failure modes of specimens were basically the same as that observed at $25^{\circ} \mathrm{C}$, except that edge splitting was noted and that the debonding area was decreased with the increase of temperature. When the temperature exceeded $45^{\circ} \mathrm{C}$, irregular fracture, instead of regular lateral fracture, became the dominant failure, with no steel-adhesive debonding observed. At $120^{\circ} \mathrm{C}$, the failure mode further changed, with the specimens being characteristic of fibrous fracture. The resin matrix that bonded fibers together at the fracture diminished, with only carbon fibers left. Fibrous fracture was also reported by Cree et al. [18] and could be observed from the result of Cao et al. [19]. Local adhesive remnant was observed on the steel plate (see point 1 in Figure 3e).

Since the service temperatures of carbon fibers and steel plates were well above $120{ }^{\circ} \mathrm{C}[23,26]$, the change in failure modes at elevated temperatures was believed to be due to the degradation of epoxy resin in mechanical properties, and moreover, the decrease of it in volume. The decrease was due to volatilization or decomposition of epoxy resin at elevated temperatures. The effects of volume decrease, which were neglected by available reports $[18,19,22,27]$, were emphasized here, since the strength and stiffness of epoxy resin kept nearly constant after the temperature exceeded $T_{\mathrm{g}}+10$ or $20{ }^{\circ} \mathrm{C}[18,19]$, while the failure mode continued to change. In other words, the degradation in mechanical properties was believed to play the key role in contributing to failure mode change only at temperatures below $T_{\mathrm{g}}+10$ or $20^{\circ} \mathrm{C}$, while after that, the volume decrease of epoxy resin was the predominant factor that affected the failure mode change. The change in failure modes could be illustrated as follows. At temperatures ranging from 30 to $40{ }^{\circ} \mathrm{C}$, the degradation was modest. No significant changes in failure modes were observed. However, when the temperature rose to $45^{\circ} \mathrm{C}$, approaching the $T_{\mathrm{g}}$, the epoxy resin started a physical transition from glassy state to rubbery state, resulting in significant decreases in strength and stiffness. The resin matrix, therefore, could not effectively unify fibers or transfer load among fibers. Fibers broke at different cross sections, and irregular fracture occurred. The degradation of epoxy resin was also the contributor of the decrease in debonding area, as the shear and peal stress in adhesive layer, which was caused by strain incompatibility between steel and CFRP under tensile load, concentrated in a more limited area than before. At $120^{\circ} \mathrm{C}$, due to high decrease in the volume of epoxy resin, fibrous fracture occurred. The local adhesive remnant on steel plate was indicative of low bonding strength between CFRP sheet and adhesive layer. Moreover, it also indicated that the local adhesive layer had lost the ability to transfer load between CFRP and steel plate.

The effects of temperatures on failure modes may be better illustrated when the failure process is taken into account. At temperatures ranging from 30 to $55^{\circ} \mathrm{C}$, noises were constantly heard in the tensile process, and the specimens failed with a sudden loud noise from the breaking of CFRP, which were similar to that observed at $25^{\circ} \mathrm{C}$. When the temperature was between 60 and $80{ }^{\circ} \mathrm{C}$, significant changes were observed. Firstly, in the preheating procedure, gases emitted from epoxy resin were detected. This observation was important as it indicated the volume decrease of epoxy resin, as mentioned above. Also, when under tensile load, the noises from specimens were considerably less audible, which indicated that the epoxy resin had softened greatly. With further temperature increase, the smell of gases emitted from preheated specimens was evidently more pungent, with the noises being observably lower. At temperatures ranging from 100 to $120{ }^{\circ} \mathrm{C}$, the color of CFRP seemed to have deepened. Noises from specimens were scarcely heard. The breaking of CFRP was only accompanied by a low and deep sound.

\subsection{Strengthening and Stiffening Effects}

Figures 4-6 show the load-displacement curves of specimens. Except for the curves of specimens $3 \mathrm{C} / \mathrm{S}$ and $3 \mathrm{C} / \mathrm{S} / \mathrm{C}$, which are the average curves based on two replicates, each curve represents the average behavior of three replicates. As noted, specimens showed bi-linear behavior before the rupture of CFRP, and the differences in their load-displacement curves laid mainly in the post-elastic region, i.e., from steel yield to CFRP rupture. 


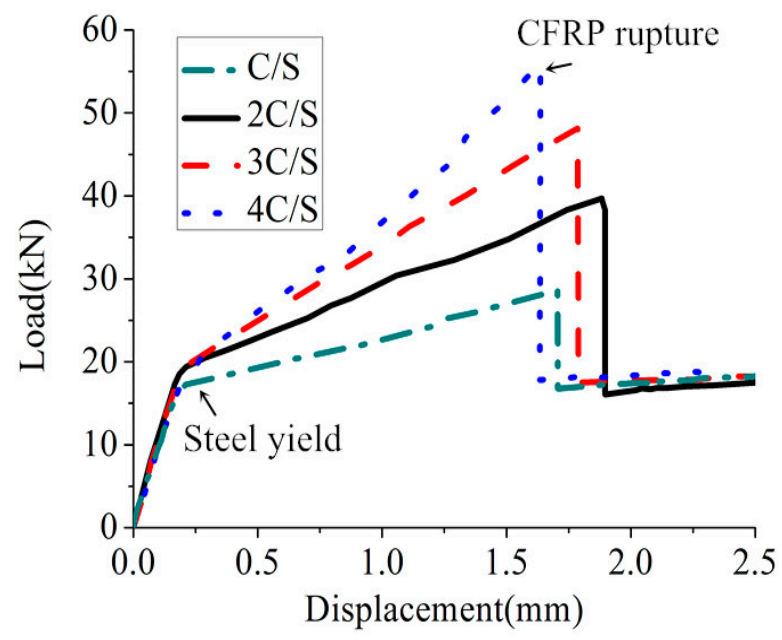

Figure 4. Load-displacement curves of series L specimens.

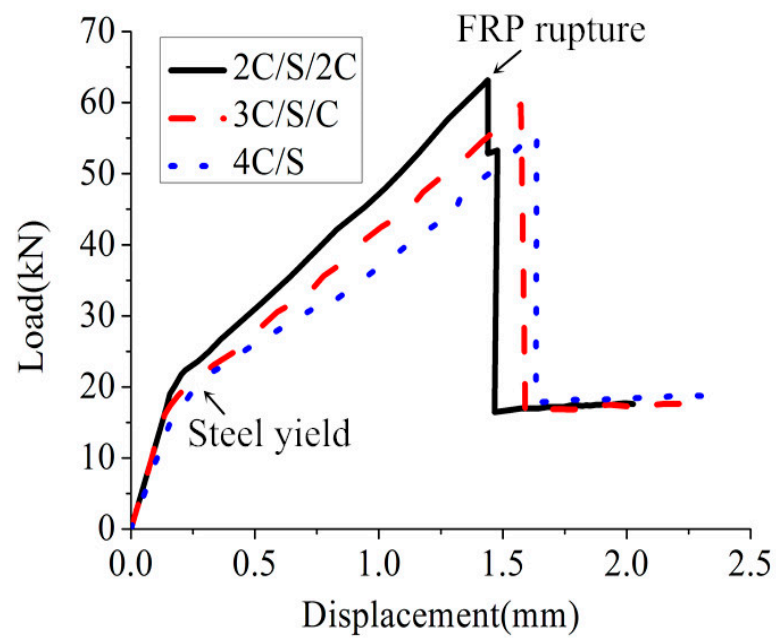

Figure 5. Load-displacement curves of series S specimens.

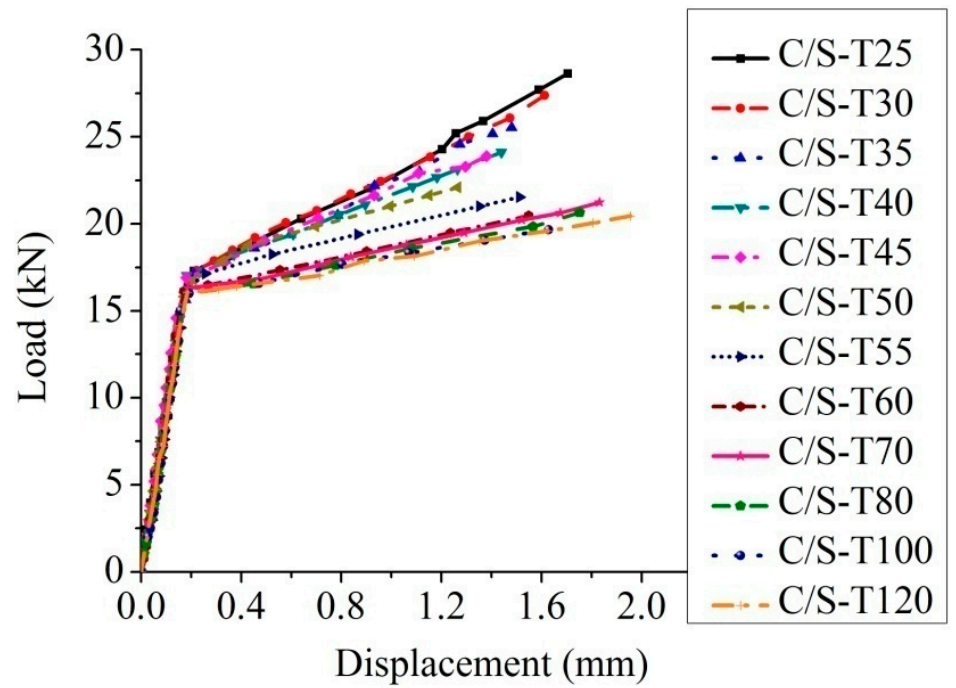

Figure 6. Load-displacement curves of series T specimens. 


\subsubsection{Effects of the Number of CFRP Layers}

Figure 7 shows the strengthening and stiffening effects of specimens with different numbers of CFRP layers. The increases in yield load and elastic stiffness were insignificant. For specimens $\mathrm{C} / \mathrm{S}$ and $4 \mathrm{C} / \mathrm{S}$, the yield loads were 17.3 and $20.2 \mathrm{kN}$, respectively, with the strength gains being $6.1 \%$ and $23.9 \%$ when compared with that of steel plates. The elastic stiffness even slightly dropped after it peaked at $2 \mathrm{C} / \mathrm{S}$, from $106.0 \mathrm{kN} / \mathrm{mm}$ at $2 \mathrm{C} / \mathrm{S}$ to $94.9 \mathrm{kN} / \mathrm{mm}$ at $4 \mathrm{C} / \mathrm{S}$. The insignificant increases, or even slight drops, in yield load and elastic stiffness were expected, since the CFRP sheet is very thin $(0.111 \mathrm{~mm})$ compared with that of steel $(2 \mathrm{~mm})$, and that the tensile modulus of CFRP is only $35 \%$ higher than that of steel. With an increase in the number of CFRP layers, more voids in adhesive layer and misalignment among fibers might occur, which weakened the contribution of CFRP to the strength and stiffness of specimens.

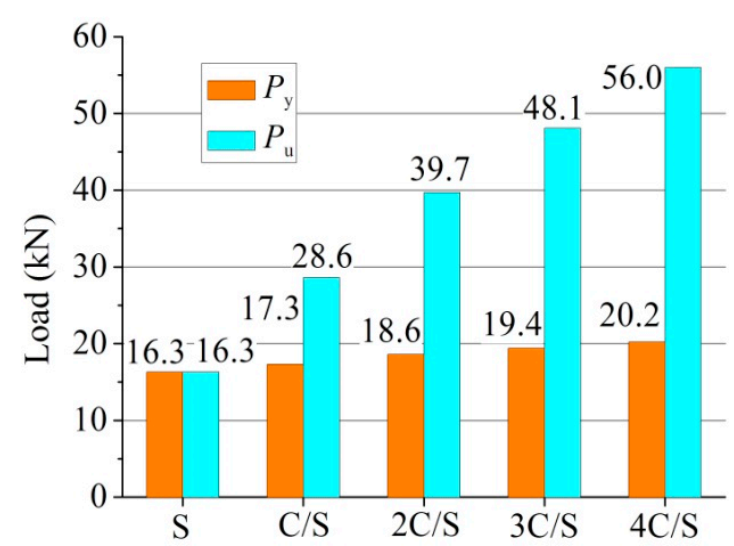

(a)

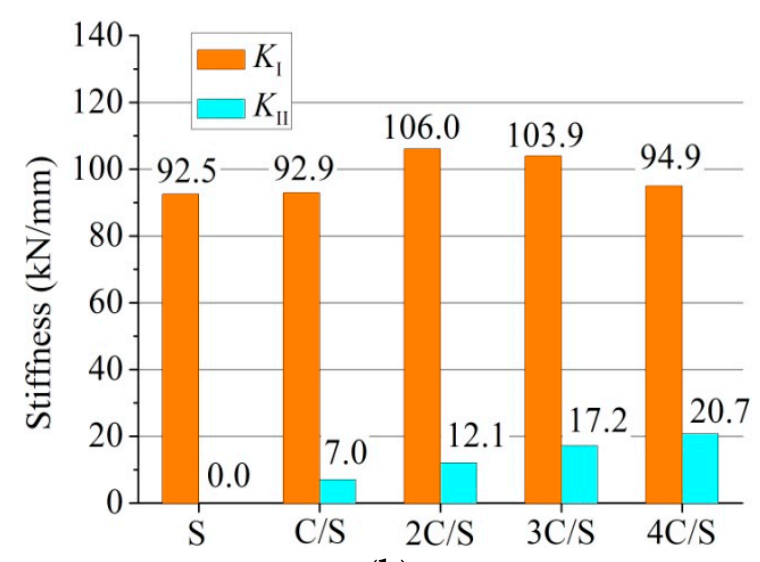

(b)

Figure 7. Effects of the number of CFRP layers: (a) yield and ultimate load of specimens; and (b) elastic and post-elastic stiffness of specimens.

In comparison, the effects on ultimate load and post-elastic stiffness were rather significant. For specimens C/S and 4C/S, the ultimate loads were 28.6 and $56.0 \mathrm{kN}$, respectively, with corresponding strength gains being $75.4 \%$ and $243.6 \%$ when compared with that of steel plates. The post-elastic stiffness also increased from nearly zero for steel plate to 7.0 and $20.7 \mathrm{kN} / \mathrm{mm}$ for specimens C/S and $4 \mathrm{C} / \mathrm{S}$, respectively. The increase in post-elastic stiffness was meaningful, as it indicated a lower permanent deformation when specimens suffered from unexpected loads.

As discussed in the introduction, conclusions vary on the strengthening efficiency, which is expressed as the average failure stress in FRP layers. The failure stresses in the present paper for specimens C/S, 2C/S, 3C/S and 4C/S were 3694, 3514, 3183, and $2980 \mathrm{MPa}$, respectively, which were $104 \%, 99 \%, 90 \%$, and $84 \%$ of the ultimate tensile strength of CFRP from coupon test. The decrease in failure stress was substantial, the causes of which might be the occurrence of voids and misalignment among fibers when more layers of CFRP were applied. The increase in the stiffness of CFRP sheets, resulting from the increase in the number of CFRP layers, might also be a contributor [28]. The stiffening efficiency, expressed as the average stiffness per FRP layer, was also decreased. The average CFRP stiffnesses for specimens $C / S, 2 C / S, 3 C / S$, and $4 C / S$ were 7.0, 6.1, 5.7, and $5.2 \mathrm{kN} / \mathrm{mm}$, respectively.

It is to be noted that a sound bonding is the prerequisite for the full utilization of CFRP strengthening materials. Al-Zubaidy [11] reported a nearly constant failure load for steel plate joints strengthened with one and three CFRP layers under impact loads. The reason behind this was that the shear strength of adhesive was exceeded and that debonding failure (adhesive failure), rather than CFRP rupture (adherend failure) occurred. 


\subsubsection{Effects of Strengthening Schemes}

Figure 8 compares the strengthening and stiffening effects of specimens with different strengthening schemes. As noted, a more balanced strengthening scheme contributed to the increase in yield and ultimate load and elastic and post-elastic stiffness. The increase in post-elastic stiffness was the most significant, as the post-elastic stiffness of specimen $2 \mathrm{C} / \mathrm{S} / 2 \mathrm{C}$ was $36 \%$ higher than that of specimen $4 \mathrm{C} / \mathrm{S}$. The elastic stiffness and ultimate load of specimen $2 \mathrm{C} / \mathrm{S} / 2 \mathrm{C}$ were $27 \%$ and $13 \%$ higher than those of specimen $4 \mathrm{C} / \mathrm{S}$, respectively. This result indicated that a more balanced (or symmetrical) strengthening scheme may help further increase mechanical properties when only a limited number of CFRP layers are available.

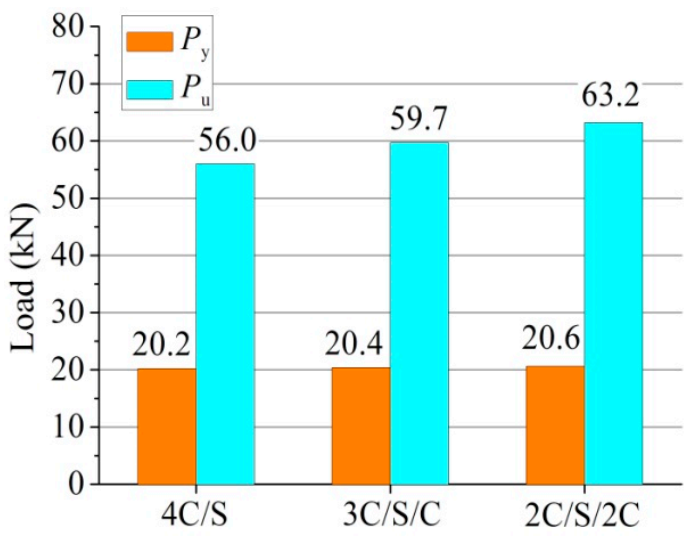

(a)

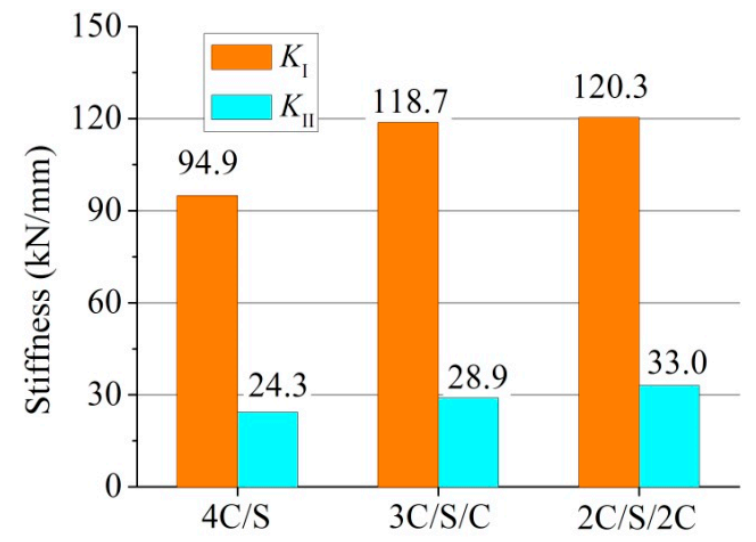

(b)

Figure 8. Effects of strengthening schemes: (a) yield and ultimate load of specimens; and (b) elastic and post-elastic stiffness of specimens.

\subsubsection{Effects of Temperature}

Figure 9 illustrates the degradation of series $\mathrm{T}$ specimens with respect to ultimate load and post-elastic stiffness at elevated temperatures. The degradation in yield load and elastic stiffness was not plotted, since the decrease was rather slight, as shown in Table 3. The insignificant decrease in yield load and elastic stiffness was due to the low content of CFRP in specimens, as the thicknesses of CFRP sheet and steel plate were 0.111 and $2 \mathrm{~mm}$, respectively.

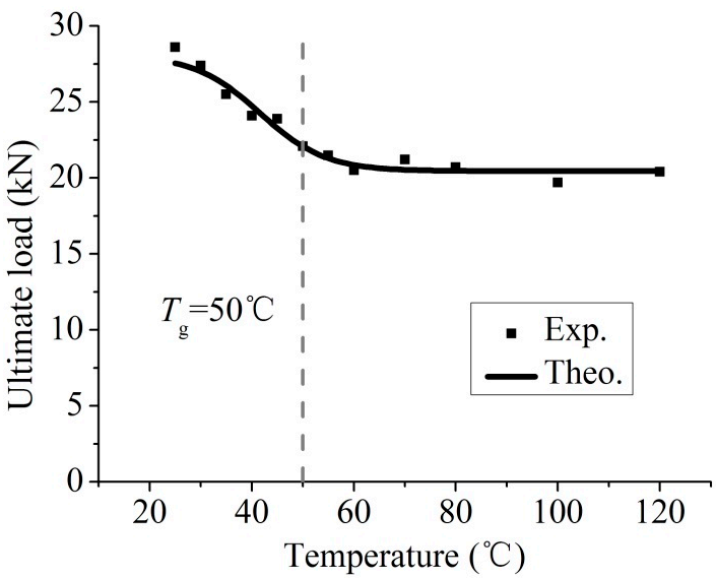

(a)

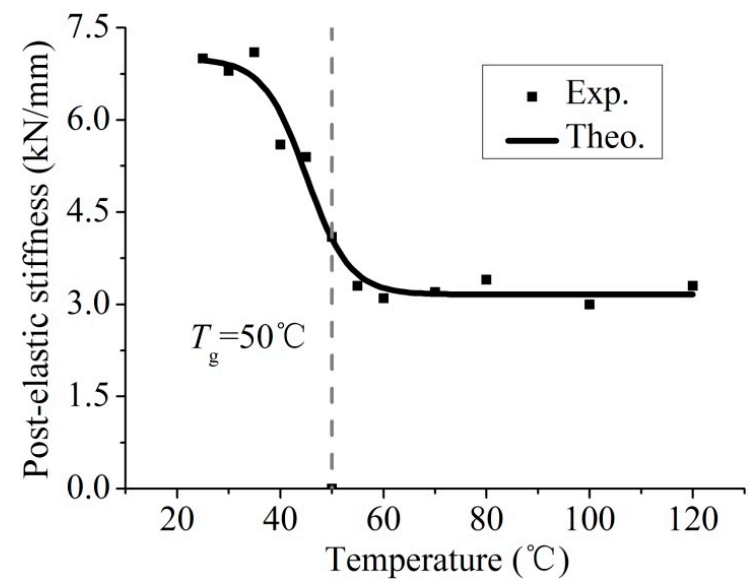

(b)

Figure 9. Effects of temperature: (a) ultimate load of specimens; and (b) post-elastic stiffness of specimens. 
It is observed that elevated temperatures resulted in a significant decrease in the ultimate load and post-elastic stiffness of specimens. As the temperature rose from 25 to $60{ }^{\circ} \mathrm{C}$, the ultimate load decreased from 28.6 to $20.5 \mathrm{kN}$, with a reduction of $28.3 \%$. Corresponding post-elastic stiffness dropped from 7.0 to $3.1 \mathrm{kN} / \mathrm{mm}$, with the reduction being $55.7 \%$. The degradation trends between ultimate load and stiffness were similar, both of which reached a peak degradation rate at about $42{ }^{\circ} \mathrm{C}$, and kept nearly constant after $60^{\circ} \mathrm{C}$. The jump in mechanical properties at about $42{ }^{\circ} \mathrm{C}$ was due to the softening of epoxy resin, as discussed previously.

\section{Analytical Modeling}

\subsection{Analytical Modeling for Tests at Ambient Temperature}

Perfect bonding is assumed between interfaces of different materials. Linear elastic model and bilinear elastic-plastic model are adopted to characterize the mechanical properties of CFRP and steel, respectively. The load bearing capacity of epoxy resin is neglected.

In the elastic region, both CFRP and steel are elastic. The Young's modulus $E_{\mathrm{I}}$ and corresponding $P_{1}$ load are as follows [29]:

$$
\begin{gathered}
E_{\mathrm{I}}=\frac{E_{\mathrm{s}} t_{\mathrm{s}}+n E_{\mathrm{f}} t_{\mathrm{f}}}{t_{\mathrm{sf}}}, 0 \leqslant \frac{\Delta}{l} \leqslant \varepsilon_{\mathrm{y}} \\
P_{\mathrm{I}}=E_{\mathrm{I}} \frac{\Delta}{l} b t_{\mathrm{sf}}, 0 \leqslant \frac{\Delta}{l} \leqslant \varepsilon_{\mathrm{y}}
\end{gathered}
$$

where $E_{\mathrm{s}}, t_{\mathrm{s}}$, and $\varepsilon_{\mathrm{y}}$ are the modulus, thickness, and yield strain of steel, respectively; $E_{\mathrm{f}}, t_{\mathrm{f}}$, and $n$ are the modulus, single-layer thickness, and number of CFRP layers, respectively; $t_{\mathrm{sf}}=t_{\mathrm{s}}+n \cdot t_{\mathrm{f}}$ and $b$ are the total thickness and the width of the specimen in the middle section, respectively; finally, $\Delta$ and $l$ are the displacement and gauge length, respectively.

In the post-elastic region, the equations for modulus $E_{\mathrm{II}}$ and corresponding load $P_{\mathrm{II}}$ are:

$$
\begin{gathered}
E_{\mathrm{II}}=\frac{n E_{\mathrm{f}} t_{\mathrm{f}}}{t_{\mathrm{sf}}}, \varepsilon_{\mathrm{y}} \leqslant \frac{\Delta}{l} \leqslant \varepsilon_{\mathrm{fu}} \\
P_{\mathrm{II}}=\left[E_{\mathrm{I}} \varepsilon_{\mathrm{y}}+E_{\mathrm{II}}\left(\frac{\Delta}{l}-\varepsilon_{\mathrm{y}}\right)\right] b t_{\mathrm{sf}}, \varepsilon_{\mathrm{y}} \leqslant \frac{\Delta}{l} \leqslant \varepsilon_{\mathrm{fu}}
\end{gathered}
$$

where $\varepsilon_{\mathrm{fu}}$ is the ultimate strain of CFRP.

After the rupture of CFRP, the tensile modus $E_{\mathrm{III}}$ is zero, with the load $P_{\mathrm{III}}$ being constant at the yield load of steel. The equations are as follows:

$$
\begin{gathered}
E_{\mathrm{III}}=0, \varepsilon_{\mathrm{fu}} \leqslant \frac{\Delta}{l} \leqslant \varepsilon_{\mathrm{su}} \\
P_{\mathrm{III}}=E_{\mathrm{I}} \varepsilon_{\mathrm{y}} b t_{\mathrm{s}}, \varepsilon_{\mathrm{fu}} \leqslant \frac{\Delta}{l} \leqslant \varepsilon_{\mathrm{su}}
\end{gathered}
$$

where $\varepsilon_{\mathrm{su}}$ is the ultimate strain of steel.

Thus, the load-displacement relationship of CFRP strengthened steel plates is derived as:

$$
P=\left\{\begin{array}{cc}
E_{\mathrm{I}} \frac{\Delta}{l} b t_{\mathrm{sf}} & 0<\frac{\Delta}{l} \leqslant \varepsilon_{\mathrm{y}} \\
{\left[E_{\mathrm{I}} \varepsilon_{\mathrm{y}}+E_{\mathrm{II}}\left(\frac{\Delta}{l}-\varepsilon_{\mathrm{y}}\right)\right] b t_{\mathrm{sf}}} & \varepsilon_{\mathrm{y}}<\frac{\Delta}{l} \leqslant \varepsilon_{\mathrm{fu}} \\
E_{\mathrm{I}} \varepsilon_{\mathrm{y}} b t_{\mathrm{s}} & \varepsilon_{\mathrm{fu}}<\frac{\Delta}{l} \leqslant \varepsilon_{\mathrm{su}}
\end{array}\right.
$$

Based on the analysis, the theoretical load-displacement curves (Theo.) were plotted and compared with the experimental curves (Exp.), as shown in Figure 10. As noted, the theoretical values agreed well with the test data. The ratios of average elastic stiffness, yield load, post-elastic 
stiffness, and ultimate load to corresponding theoretical values were $0.919,0.971,0.929$, and 0.948, with the coefficients of variation (CV) being $0.102,0.017,0.161$, and 0.059 , respectively. Differences between theoretical and experimental curves were mainly due to voids in the adhesive layer and the incompatibility in strain of CFRP and steel after the yielding of steel, neither of which were considered in the analytical model.

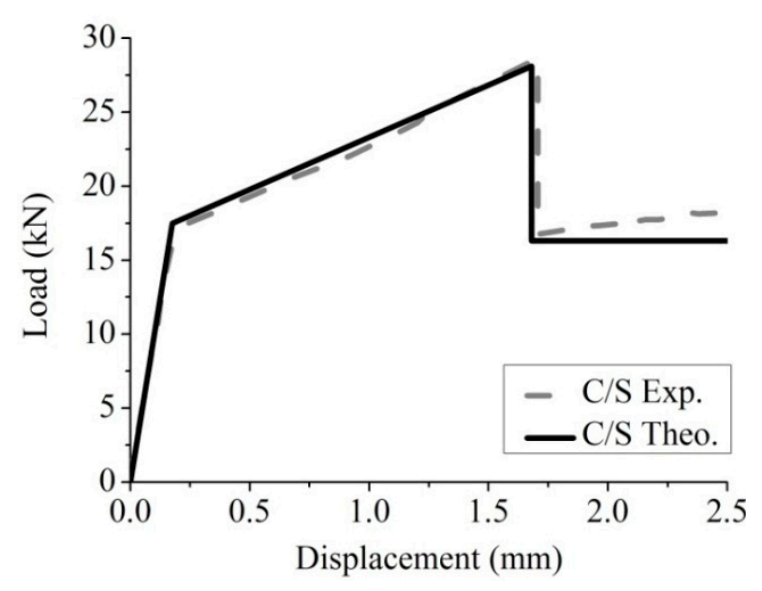

(a)

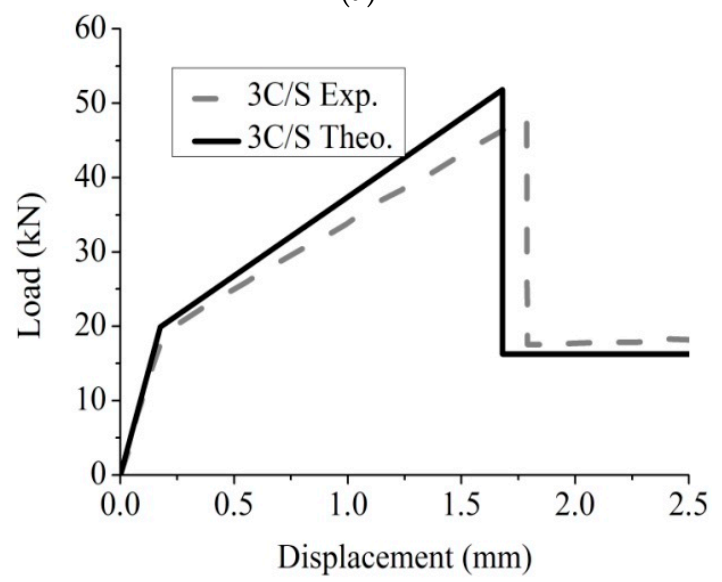

(c)

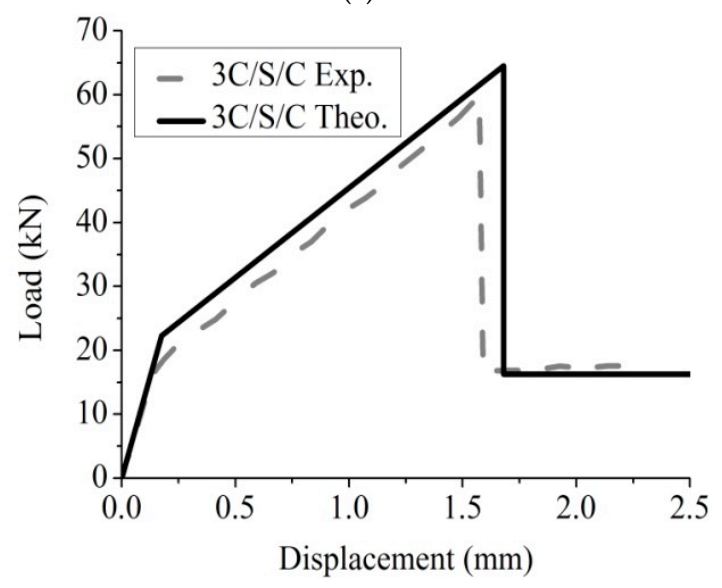

(e)

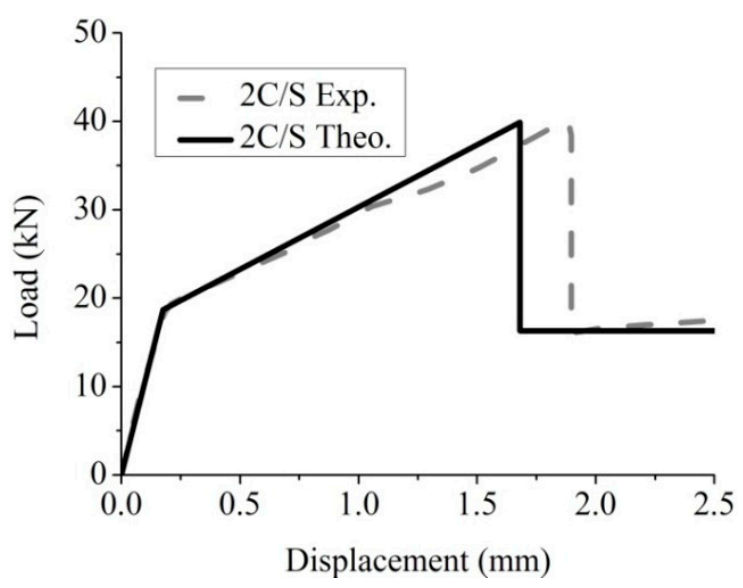

(b)

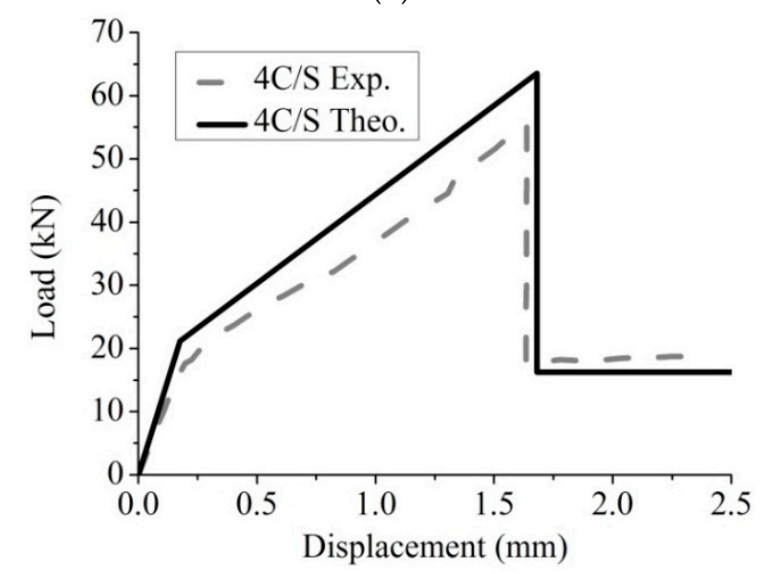

(d)

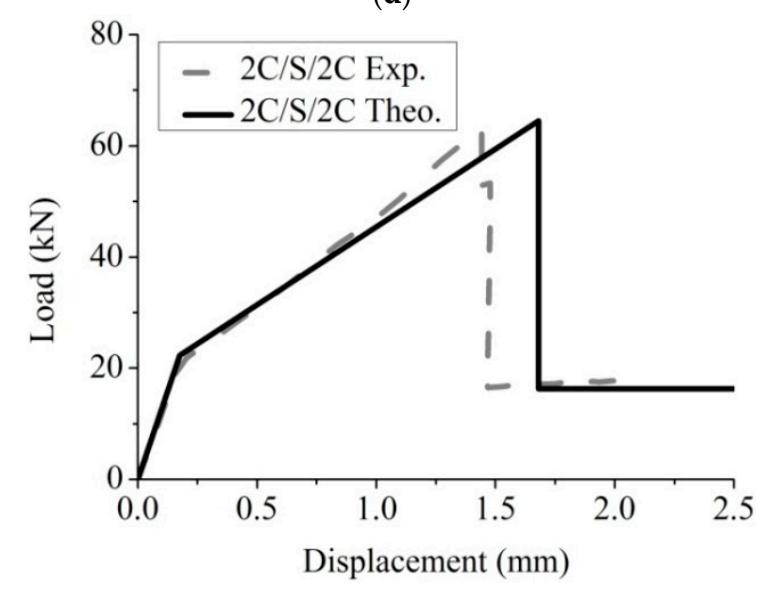

(f)

Figure 10. Load-displacement curves of series $L$ and $S$ specimens (a) $C / S$; (b) $2 C / S$; (c) $3 C / S$; (d) $4 \mathrm{C} / \mathrm{S} ;$ (e) $3 \mathrm{C} / \mathrm{S} / \mathrm{C}$; and (f) $2 \mathrm{C} / \mathrm{S} / 2 \mathrm{C}$. 


\subsection{Analytical Modeling for Tests at Elevated Temperatures}

As the degradation of yield load and elastic stiffness were modest, the modeling was focused on the degradation of ultimate load and post-elastic stiffness. Similar to the case for the modeling of tests at ambient temperature, linear elastic model and bilinear elastic-plastic model are adopted for characterizing the mechanical properties of CFRP and steel, respectively. The load-bearing capacity of epoxy resin is neglected. The yield load of steel is assumed to be constant within the temperature range studied [23]. A simplified model of Mouritz and Gibson [20] was adopted by assuming $R^{n}$ to be one.

Thus, the expressions for ultimate loads of CFRP and the whole specimen are as follows:

$$
\begin{gathered}
f_{\mathrm{f}}(T)=\frac{f_{\mathrm{U}}+f_{\mathrm{R}}}{2}-\frac{f_{\mathrm{U}}-f_{\mathrm{R}}}{2} \tanh \left(k_{\mathrm{a}}\left(T-T_{\mathrm{a}}^{\prime}\right)\right) \\
P_{\mathrm{u}}(T)=f_{\mathrm{f}}(T) A_{\mathrm{f}}+f_{\mathrm{y}} A_{\mathrm{s}}
\end{gathered}
$$

where $P_{\mathrm{u}}(T)$ is the ultimate load at temperature $T ; f_{\mathrm{R}}, k_{\mathrm{a}}$, and $T_{\mathrm{a}}{ }^{\prime}$ are constants achieved through regression analysis, which are $1258.91,0.078$, and 41.6 , respectively, in the present paper.

The post-elastic stiffness is calculated as:

$$
k_{\mathrm{II}}(T)=\frac{k_{\mathrm{U}}+k_{\mathrm{R}}}{2}-\frac{k_{\mathrm{U}}-k_{\mathrm{R}}}{2} \tanh \left(k_{\mathrm{b}}\left(T-T_{\mathrm{b}}^{\prime}\right)\right)
$$

where $k_{\mathrm{II}}(T)$ is the ultimate load at temperature $T ; k_{\mathrm{R}}, k_{\mathrm{b}}$, and $T_{\mathrm{b}}{ }^{\prime}$ are constants achieved through regression analysis, which are $3.16,0.120$, and 45.1 , respectively, in the present paper.

The modeling results were listed in Table 3 and compared with experimental values, as shown in Figure 9. It could be observed that the fitting curves matched well with the test data. The average value of experimental data to theoretical data for ultimate load and post-elastic stiffness were 1.000 and 0.994 , respectively, with corresponding CVs being 0.05 and 0.02 .

However, it is to be noted that the good fit is based on test data in the present paper. As the mechanical properties of different resins vary greatly at elevated temperatures, the coefficients obtained from regression analysis need to be validated with further research.

\section{Conclusions}

Based on experimental tests, the following conclusions are drawn:

(1) The effects of the number of CFRP layers and strengthening schemes on failure modes of CFRP strengthened steel plates under tensile load were insignificant. The failure modes were mainly affected by the experimental temperature. The change in failure modes was dominated by the degradation of resin matrix in mechanical properties when the temperature was below $T_{\mathrm{g}}+10$ or $20^{\circ} \mathrm{C}$; and was also dominated by the volume decrease of resin matrix at temperatures above that. The volume decrease was due to resin volatilization or decomposition at elevated temperatures;

(2) The number of CFRP layers, strengthening schemes, and experimental temperatures mainly affected the load-displacement behavior of specimens in the post-elastic region, while their influences on the elastic region were relatively modest;

(3) The ultimate load and post-elastic stiffness of specimens significantly increased with the number of CFRP layers. The ultimate load bearing capacity was 28.6, 39.7, 48.1, and $56 \mathrm{kN}$ for specimens strengthened with one, two, three, and four layers of CFRP sheets, respectively. The post-elastic stiffnesses were correspondingly 7.0,12.1, 17.2, and $20.7 \mathrm{kN} / \mathrm{mm}$, respectively. However, the strengthening and stiffening efficiency decreased with the increase in number of CFRP layers. The average failure stresses in CFRP for specimens C/S, 2C/S, 3C/S, and 4C/S were 3694, 3514, 3183, and $2980 \mathrm{MPa}$, respectively, with corresponding stiffness in CFRP being 7.0, 6.1, 5.7, and $5.2 \mathrm{kN} / \mathrm{mm}$, respectively. 
(4) The double-sided strengthening scheme had better strengthening and stiffening effects than the single-sided strengthening scheme. The ultimate load and post-elastic stiffness of specimen $2 \mathrm{C} / \mathrm{S} / 2 \mathrm{C}$ were $13 \%$ and $36 \%$ higher than those of specimen $4 \mathrm{C} / \mathrm{S}$, respectively;

(5) The ultimate load and post-elastic stiffness were significantly decreased at elevated temperatures. The values of ultimate load and post-elastic stiffness at $60{ }^{\circ} \mathrm{C}$, after which the values kept nearly constant, were only $44.3 \%$ and $71.7 \%$ of the values at ambient temperature; and

(6) Analytical modeling for predicting the load-displacement behavior at ambient temperature and the ultimate load and post-elastic stiffness at elevated temperatures were conducted. The modeling results were verified by the test data.

Acknowledgments: The authors would like to appreciate the financial support by the Young Scientist Project of the Natural Science Foundation of China (51108355), the Natural Science Foundation of Hubei Province, China (2011CDB269), and the Fundamental Research Funds for the Central Universities of China (2015210020201).

Author Contributions: This paper was accomplished based on collaborative work of the authors. Weijie Li and Xiaojin Li designed the experiment with the help of Yiyan Lu and Shan Li. Weijie Li, Xiaojin Li, and Tao Zhu performed the test under the supervision of Yiyan Lu and Shan Li. Weijie Li analyzed the data and wrote the paper.

Conflicts of Interest: The authors declare no conflict of interest.

\section{References}

1. Teng, J.G.; Chen, J.F.; Smith, S.T.; Lam, L. Behaviour and strength of FRP-strengthened RC structures: A state-of-the-art review. Proc. Inst. Civ. Eng. Struct. Build. 2003, 156, 51-62. [CrossRef]

2. Aslam, M.; Shafigh, P.; Jumaat, M.Z.; Shah, S.N.R. Strengthening of RC beams using prestressed fiber reinforced polymers-A review. Constr. Build. Mater. 2015, 82, 235-256. [CrossRef]

3. Zhao, X.; Zhang, L. State-of-the-art review on FRP strengthened steel structures. Eng. Struct. 2007, 29, 1808-1823. [CrossRef]

4. Teng, J.G.; Yu, T.; Fernando, D. Strengthening of steel structures with fiber-reinforced polymer composites. J. Constr. Steel Res. 2012, 78, 131-143. [CrossRef]

5. Sen, R.; Liby, L.; Mullins, G. Strengthening steel bridge sections using CFRP laminates. Compos. Eng. 2001, 32, 309-322. [CrossRef]

6. Al-Saidy, A.H.; Klaiber, F.W.; Wipf, T.J. Strengthening of steel-concrete composite girders using carbon fiber reinforced polymer plates. Constr. Build. Mater. 2007, 21, 295-302. [CrossRef]

7. Fam, A.; MacDougall, C.; Shaat, A. Upgrading steel-concrete composite girders and repair of damaged steel beams using bonded CFRP laminates. Thin Wall. Struct. 2009, 47, 1122-1135. [CrossRef]

8. Schnerch, D.; Rizkalla, S. Flexural strengthening of steel bridges with high modulus CFRP strips. J. Bridge. Eng. 2008, 2, 192-201. [CrossRef]

9. Miller, T.C.; Chajes, M.J.; Mertz, D.R.; Hastings, J.N. Strengthening of a steel bridge girder using CFRP plates. J. Bridge. Eng. 2001, 6, 514-522. [CrossRef]

10. Colombi, P.; Poggi, C. Strengthening of tensile steel members and bolted joints using adhesively bonded CFRP plates. Constr. Build. Mater. 2006, 20, 22-33. [CrossRef]

11. Al-Zubaidy, H.; Al-Mahaidi, R.; Zhao, X. Experimental investigation of bond characteristics between CFRP fabrics and steel plate joints under impact tensile loads. Compos. Struct. 2012, 94, 510-518. [CrossRef]

12. Bocciarelli, M.; Colombi, P.; Fava, G.; Poggi, C. Fatigue performance of tensile steel members strengthened with CFRP plates. Compos. Struct. 2009, 87, 334-343. [CrossRef]

13. Liu, H.; Al-Mahaidi, R.; Zhao, X. Experimental study of fatigue crack growth behaviour in adhesively reinforced steel structures. Compos. Struct. 2009, 90, 12-20. [CrossRef]

14. Li, Y.; Wang, Y.; Ou, J. Mechanical behavior of BFRP-steel composite plate under axial tension. Polymers 2014, 6, 1862-1876. [CrossRef]

15. Tavakkolizadeh, M.; Saadatmanesh, H. Strengthening of steel-concrete composite girders using carbon fiber reinforced polymers sheets. J. Struct. Eng. 2003, 129, 30-40. [CrossRef]

16. Lu, Y.; Zhang, H.; Liu, S. Experimental study on tensile properties of steel plate bonded by CFRP. J. Wuhan Univ. Technol. Mater. Sci. Ed. 2008, 23, 727-732. [CrossRef] 
17. Suli, L. Experimental Research on Mechanism of Bond between Carbon Fiber Reinforced Polymer and Steel Plate. Master's Thesis, Wuhan University, Wuhan, China, November 2004.

18. Cree, D.; Gamaniouk, T.; Loong, M.L.; Green, M.F. Tensile and lap-splice shear strength properties of CFRP composites at high temperatures. J. Compos. Constr. 2014. [CrossRef]

19. Cao, S.; Wu, Z.; Wang, X. Tensile properties of CFRP and hybrid FRP composites at elevated temperatures. J. Compos. Mater. 2009, 43, 315-330.

20. Mouritz, A.P.; Gibson, A.G. Fire Properties of Polymer Composite Materials; Springer: Dordrecht, The Netherlands, 2006; pp. 175-180.

21. Chowdhury, E.U.; Eedson, R.; Bisby, L.A.; Green, M.F.; Benichou, N. Mechanical characterization of fibre reinforced polymers materials at high temperature. Fire. Technol. 2011, 47, 1063-1080. [CrossRef]

22. Nguyen, T.; Bai, Y.; Zhao, X.; Al-Mahaidi, R. Mechanical characterization of steel/CFRP double strap joints at elevated temperatures. Compos. Struct. 2011, 93, 1604-1612. [CrossRef]

23. Li, G.; Wang, P. Advanced Analysis and Design for Fire Safety of Steel Structures; Springer: New York, NY, USA, 2013; pp. 48-50.

24. Metallic Materials_Tensile Testing_Part 1: Method of Test at Room Temperature; ISO 6892-1:2009; BSI: London, UK, 2009.

25. Standard Test Method for Tensile Properties of Polymer Matrix Composite Materials; ASTM D3039-07; ASTM: West Conshohocken, PA, USA, 2008.

26. Campbell, F.C. Structural Composite Materials; ASM International: Materials Park, OH, USA, 2010; p. 49.

27. Tan, K.H.; Zhou, Y. Performance of FRP-strengthened beams subjected to elevated temperatures. J. Compos. Constr. 2011, 15, 304-311. [CrossRef]

28. Qingrui, Y.; Yongxin, Y. The Application of FRP in Structures' Strengthening and Retrofitting; Chemical Industry Press: Beijing, China, 2006; p. 172.

29. Kulkarni, R.R.; Chawla, K.K.; Vaidya, U.K.; Koopman, M.C.; Eberhardt, A.W. Characterization of long fiber thermoplastic/metal laminates. J. Mater. Sci. 2008, 43, 4391-4398. [CrossRef]

(C) 2015 by the authors; licensee MDPI, Basel, Switzerland. This article is an open access article distributed under the terms and conditions of the Creative Commons by Attribution (CC-BY) license (http://creativecommons.org/licenses/by/4.0/). 